\title{
THE EFFECT OF CHANGE OF TEMPERATURE ON THE BASAL METABOLISM OF SWINE.
}

\author{
BY J. W. CAPSTICK, O.B.E., M.A., \\ Fellow of Trinity College, \\ AND \\ T. B. WOOD, C.B.E., M.A., F.R.S., \\ Drapers' Professor of Agriculture. \\ (From the Animal Nutrition Institute, School of \\ Agriculture, Cambridge.)
}

\section{INTRODUCTION.}

IT has long been generally accepted that an animal requires more food in cold weather than in hot weather, that, in fact and within certain limits, an animal's food requirement increases as the temperature falls. The number of precise measurements however of the effect of change of temperature on food requirement is very small, and it was with the object of extending the knowledge of this important subject that the following investigation was undertaken.

The writers' attention was directed to the subject by a paper by Armsby and Fries on "Net Energy Values and Starch Values" which appeared in this Journal in $1919^{1}$.

In this paper Armsby and Fries point out that their Net Energy and Kellner's Starch Equivalents really measure the same thing, namely the amount of energy in feeding stuffs which is available to the animal for physiological purposes. They claim further however that this net energy only is available for maintenance, and that any excess of energy above this amount is converted at once into heat which is of no value to the animal.

The point will perhaps be made clearer by a concrete instance, and since figures on the subject are lacking in the case of swine, it may be permissible to supply them for a steer.

Armsby states that the basal metabolism of a 1,000 lb. steer is about six therms or 6,000 calories per day. Most European authorities agree that 14: lbs. of average meadow hay supplies a maintenance ration for a

1 This Journal, 9, 182. 
$1,000 \mathrm{lb}$. steer. Now $14 \mathrm{lbs}$. of average meadow hay supplies about 11,500 calories of metabolisable energy and about 6,000 calories of net energy. Armsby and Fries contend that only the 6,000 calories of net energy are of service to the animal, the remaining 5,500 calories being wasted. Many European writers, amongst them one of the authors (T. B. W.), have assumed that under certain conditions the whole 11,500 calories may be of service to the steer, the 6,000 calories of net energy sufficing for physiological purposes, which presumably will not vary greatly with changes of temperature, and the balance of 5,500 calories saving the oxidation of further material to meet the increased energy required to maintain body temperature in unusually cold surroundings. It is significant to note that whilst Armsby's measurements were made in general in a calorimeter at about $65^{\circ} \mathrm{F}$. or summer temperature, most European experiments on the maintenance of steers have been made in unheated stalls or sheds at winter temperatures of between $40^{\circ} \mathrm{F}$. and $50^{\circ} \mathrm{F}$. Such a difference in temperature, amounting to from 8 to $14^{\circ} \mathrm{C}$. may possibly account for the difference of opinion between American and European investigators. It was with the hope of throwing some light on this point that the writers undertook the investigation described in the following pages. Unfortunately their calorimeter was not large enough to allow of experiments with a $1,000 \mathrm{lb}$. steer. The experiments were therefore carried out on a hog.

The investigation also deals with another point. Previous investigations on the effect of temperature on metabolism have shown that at ordinary temperatures an animal maintains its body temperature approximately constant by the rearrangement of its blood circulation. When the air temperature is low, the blood is deflected from the skin to the internal organs: the skin gets cold and loses less heat, but the internal temperature is maintained. When the air temperature is high much blood is sent through the skin where it loses much heat and cools the internal organs.

This method of regulation is however insufficient to maintain a constant body temperature when the air temperature falls beluw a certain point which has been called the critical temperature. Below this point, a fall in the air temperature necessitates the oxidation of further material. The basal metabolism will therefore attain a minimum at the so-called critical point. Below this point it will increase by the heat value of the extra material oxidised. 


\section{ExperimentaL.}

The experiments described below were carried out in the large calorimeter described by one of the writers (J. W. C.) in a previous number of this Journal' ${ }^{2}$. As the method of working is fully described in that paper nothing need be said here as to the details of the manipulation.

The experiments were made on a Large White pedigree hog bred by Mr K. J. J. Mackenzie on the Cambridge University Farm. The hog was born on January 26th, 1921, and was castrated on April 1st. The experiments began at the end of November when the hog was 10 months old and continued to the following April.

The food given to the hog was of the same general character throughout the experiments and was gradually increased so as to be roughly proportional to the two-thirds power of his weight. As an indication of the nature and amount of his food, he received when his weight was $300 \mathrm{lbs}$. the following daily ration in two meals:

$$
\begin{array}{ll}
2 \text { lbs. sharps, } & 2 \text { lbs. barley meal, } \\
1 \frac{1}{2} \text { lbs. bean meal, } & 1 \mathrm{lb} \text {. maize meal, }
\end{array}
$$

$1 \mathrm{lb}$. fish meal.

In the intervals between the fasting periods, which lasted from four to six days, he was kept in a small paddock in the open air with a shelter of wattle hurdles. In severe weather he was put in a sty in the laboratory. As he stripped his paddock bare of vegetation very quickly he was given a little green food each day.

The care of the hog was in the hands of Capt. J. S. Morgan who kept him in excellent condition throughout. The fact that the hog gained $157 \mathrm{lbs}$. in weight in the course of the experiments, which lasted 140 days, in spite of his being without food for about a quarter of that time, is sufficient indication that the fasts had no ill-effect on his health.

The hog was put in the calorimeter about 9 a.m. and remained there in darkness and without food, usually for five days. Regular supplies of water were introduced from outside. During this period readings were taken whenever the galvanometer curve showed that he had been asleep for a sufficiently long time to get rid of the effects of muscular activity. From these readings the heat evolution was calculated. No analyses were made of the excreta nor was the respiratory exchange observed.

After each fasting period he was given about a fortnight to recover 
before being put in the calorimeter again. This proved to be long enough to keep him in good health.

The heat given off by the hog was measured in the usual way by observing the rise of temperature of a stream of water circulating round the calorimeter, additions being made for the latent heat of the water vapour brought out in the ventilating air, for the sensible heat brought away by the ventilating air and for leakage of heat through the walls of the calorimeter.

Details of the apparatus and the methods of measurement are given in the paper quoted above. It is sufficient to say here that the rise of temperature of the circulating water is measured by a thermoelectric couple which traces a continuous record on a Cambridge and Paul Thread Recording Galvanometer. This continuous record has proved to be a very valuable feature of the apparatus. The writers consider that it has enabled them to obtain more accurate measurements of the true Resting Metabolism than have been obtained hitherto.

The curve shows at a glance whether the hog is asleep or not, how long he has been asleep and whether his metabolism is rising or falling. The slightest movement of the hog is recorded at once and the nature of the bump on the curve often reveals its cause. An instance of this is given in Fig. 1.

Moreover there are occasional lapses in the apparatus. An electric current may fail through a bad contact or other cause. The thermostat may strike work through a heater burning out, dirty mercury causing the relay to go out of action, etc. After some experience it has been found that all these have their characteristic effects on the curve, so that an observer watching the galvanometer can go at once to the source of the trouble and remove it before any harm is done.

In the earlier experiments the hog was very regular in his habits. He seldom slept in the day-time but kept in continual motion, his metabolism being very irregular and mounting gradually higher until about 5.30 or 6 p.m. when he went to sleep, and usually did not stir antil about 6 o'clock on the following morning, except that at some time in the earlier part of the night he stood up to empty his bladder.

Fig. 1 is the curve obtained on the second day of the experiment which began on January 5. It has been chosen as showing several of the characteristic features of these curves. The irregularity of the curve in the day-time is much the same as is found in most of the curves, except on the first day of the fast when the hog often slept a part of the day.

The small hump at 10.30 p.m. is due to the hog's rising to empty 
Journal of Agricultural Science, Vol. xrr. Part 3

Jan. 6th, 1922

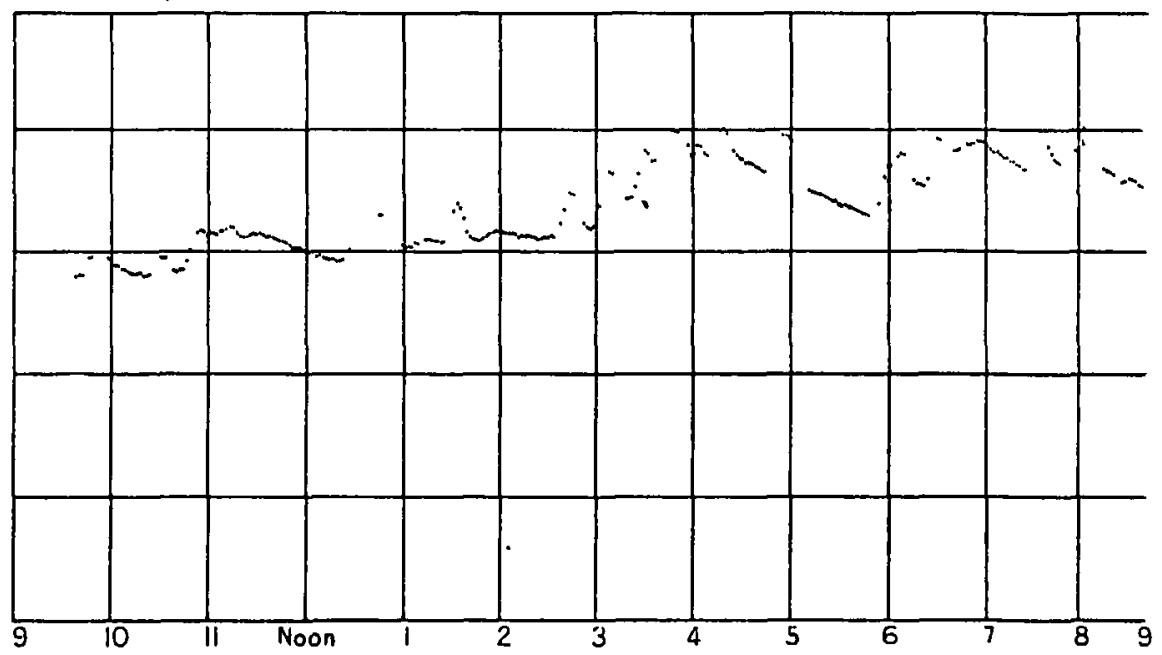

between pp. $260-261$ 
Jan. 7th, 1922

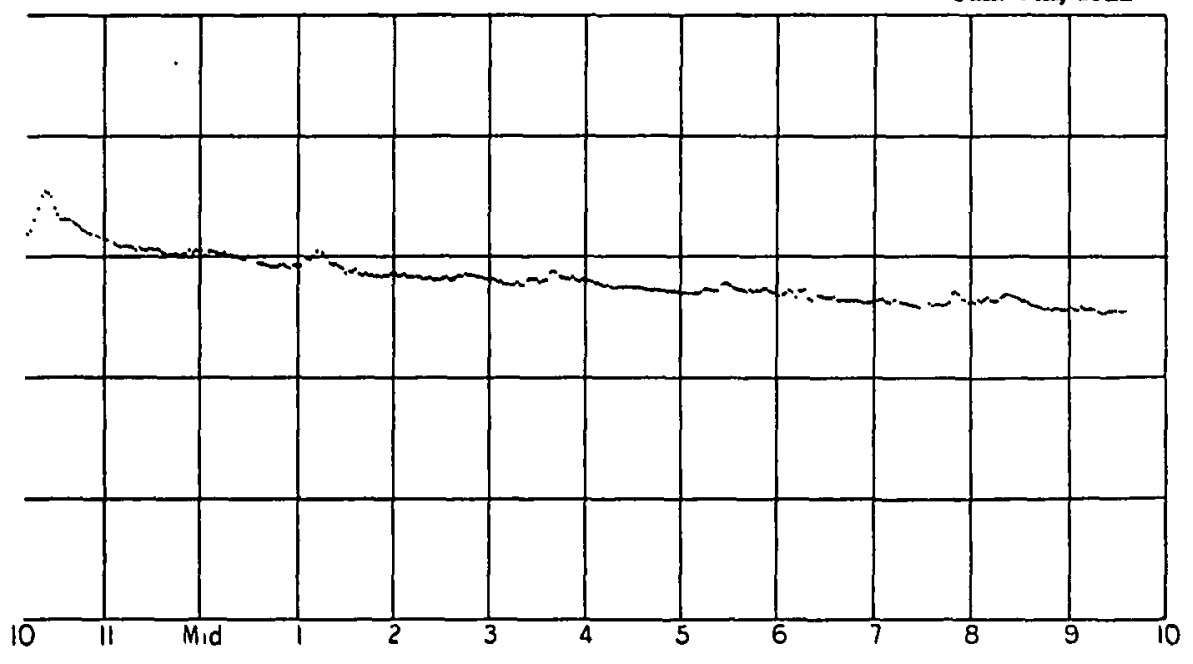


his bladder. Its shape is quite characteristic of urination. The warm urine falling on the floor of the calorimeter causes a rapid rise in the temperature of the outlet water followed by an equally rapid fall as the urine cools. This fall is checked by the rise of metabolism due to the movement of the hog, which does not show itself so quickly as the rise due to the warm urine.

The peak at 1.15 a.m. was caused by a small movement of the hog.

It is obvious that it is impossible to take any measurements of the resting metabolism in the day-time or the earlier part of the night. When the hog has gone to sleep it takes many hours for the metabolism to sink to its correct resting value uncomplicated by the effects of muscular activity. The fall during the night is not entirely due to recovery from the day's activity. It is prolonged by the lag in the galvanometer readings arising from the heat capacity of the calorimeter. This heat capacity, whilst not altering the total area of a hump, reduces its height and spreads it over a greater time. Further it is known that the body temperature in man falls to a minimum in the early hours of the morning and it is possible that there is a similar fall in swine which would in itself cause a fall in the heat evolution during the night.

The final conclusion from the study of these galvanometer curves is that it is only on rare occasions that observations of the resting metabolism free from the effect of muscular activity can be made at any other time than in the early hours of the morning.

The galvanometer records have been taken continuously through the whole period of the fast. The readings of the various thermometers, etc. needed for calculating the heat evolution have in general not been taken during the day. Through the night they have been taken at hourly or occasionally at half-hourly intervals, unless the curve showed thit the readings would be useless. At the end of each day the curve and :he record of the readings were carefully studied to find the time or timis at which the metabolism most nearly approached a steady minimun It is not possible to be biased in making the selection for the calculai ion is so long and involves so many readings that it is quite impossible tc foresee the result before the calculation is completed. Most frequently only one point was selected from the day's recordsoccasionally two 0 - three-on a few occasions no point showed sufficient steadiness. The $m \in$ abolism was in a few cases calculated at points within 24 hours of th ' hog's entering the calorimeter, but these early readings have less weigh ${ }^{2}$ than those taken later. The hog never really settled down until the sea nd night. 
Experiments have been made at a series of temperatures ranging trom $10.3^{\circ} \mathrm{C}$. to $23 \cdot 7^{\circ} \mathrm{C}$.

It is not possible to state exactly what was the temperature of the hog's surroundings. Take for instance the experiment at what we have called $13.3^{\circ}$ in Fig. 2 . The water entered the circulating pipe at $13.3^{\circ}$ and left it at $13.5^{\circ}$. The average temperature of the calorimeter body was therefore somewhere between these temperatures. The ventilating air entered the calorimeter at $12.4^{\circ}$ and left at $14.4^{\circ}$. What then was the effective temperature of the calorimeter from the point of view of the hog's metabolism? One can only make a guess. In order to have something definite the writers have adopted the temperature of the inlet water as defining the temperature of the hog's surroundings, fully realising that the actual effective temperature is probably a little different. The point is not one of any great consequence as the critical temperature is rather indefinite. It is not strictly a temperature but a set of circumstances of which temperature is the most important, for air circulation, humidity, etc. are not without effect.

\section{Table I.}

The time is given in hours since the last meal.

In the $23.7^{\circ}$ experiment the earlier readings were lost through a defect in the galvanometer circuit.

\begin{tabular}{|c|c|}
\hline & $\begin{array}{l}\text { te Dec. } 4 \\
\text { ght } 216 \mathrm{lbs} \\
\text { op. } 13 \cdot 3^{\circ}\end{array}$ \\
\hline Time & Metabolism \\
\hline $\begin{array}{r}14 \\
43 \\
66 \\
93 \\
116 \\
140\end{array}$ & $\begin{array}{l}2.927 \\
2.139 \\
1.926 \\
1.852 \\
1.833 \\
1.851\end{array}$ \\
\hline
\end{tabular}

\begin{tabular}{|c|c|c|c|}
\hline \multicolumn{2}{|c|}{$\begin{array}{l}\text { Date Dec. } 19 \\
\text { Weight } 231 \mathrm{lbs} \\
\text { Temp. } 16.9^{\circ}\end{array}$} & \multicolumn{2}{|c|}{$\begin{array}{c}\text { Date Jan. } 8 \\
\text { Weight } 252 \text { lbs } \\
\text { Temp. } 10 \cdot 3^{\circ}\end{array}$} \\
\hline Time & Metabolism & Time & Metabolism \\
\hline $\begin{array}{r}41 \\
67 \\
90 \\
114\end{array}$ & $\begin{array}{l}2.058 \\
1.869 \\
1.702 \\
1.725\end{array}$ & $\begin{array}{l}19 \\
42 \\
66 \\
90\end{array}$ & $\begin{array}{l}3 \cdot 188 \\
2 \cdot 374 \\
2 \cdot 227 \\
2 \cdot 105\end{array}$ \\
\hline
\end{tabular}

\begin{tabular}{|c|c|}
\hline & $\begin{array}{l}\text { te Feb. } 5 \\
\text { bt } 293 \text { lbs } \\
\text { mp. } 20 \cdot 4^{\circ}\end{array}$ \\
\hline ime & Metabolism \\
\hline $\begin{array}{r}35 \\
39 \\
65 \\
114\end{array}$ & $\begin{array}{l}1.927 \\
1.904 \\
1.702 \\
1.562\end{array}$ \\
\hline
\end{tabular}

$\begin{array}{cc}\begin{array}{c}\text { Date Feb. } 25 \\ \text { Weight } 306 \mathrm{lbs} \\ \text { Temp. } 13 \cdot 6^{\circ}\end{array} \\ \text { Time } & \text { Metrbolism } \\ 45 & 2 \cdot 221 \\ 68 & 2.019 \\ 93 & 1.955 \\ 113 & 1.936\end{array}$

\begin{tabular}{|c|c|}
\hline \multicolumn{2}{|c|}{$\begin{array}{c}\text { Date Mar. } 22 \\
\text { Weight } 342 \mathrm{lbs} \\
\text { Temp. } 12 \cdot 8^{\circ}\end{array}$} \\
\hline Time & Metabolism \\
\hline $\begin{array}{r}28 \\
38 \\
58 \\
108 \\
134\end{array}$ & $\begin{array}{l}2 \cdot 647 \\
2 \cdot 438 \\
2 \cdot 266 \\
2 \cdot 126 \\
2 \cdot 115\end{array}$ \\
\hline
\end{tabular}

Date Apr. 23

Weight $373 \mathrm{lbs}$

Temp. $23 \cdot 7^{\circ}$

Time Metabolism

$63 \quad 1.870$

$84 \quad 1.750$

Table I shows the whole of the observations that have been made. At the head of each section is given the date on which the hog left the calorimeter, his weight at the end of the fast before receiving his first 
meal and the temperature of the inlet water. Below these data is given the calculated metabolism in kilogram-calories per minute at various numbers of hours from the hog's last meal.

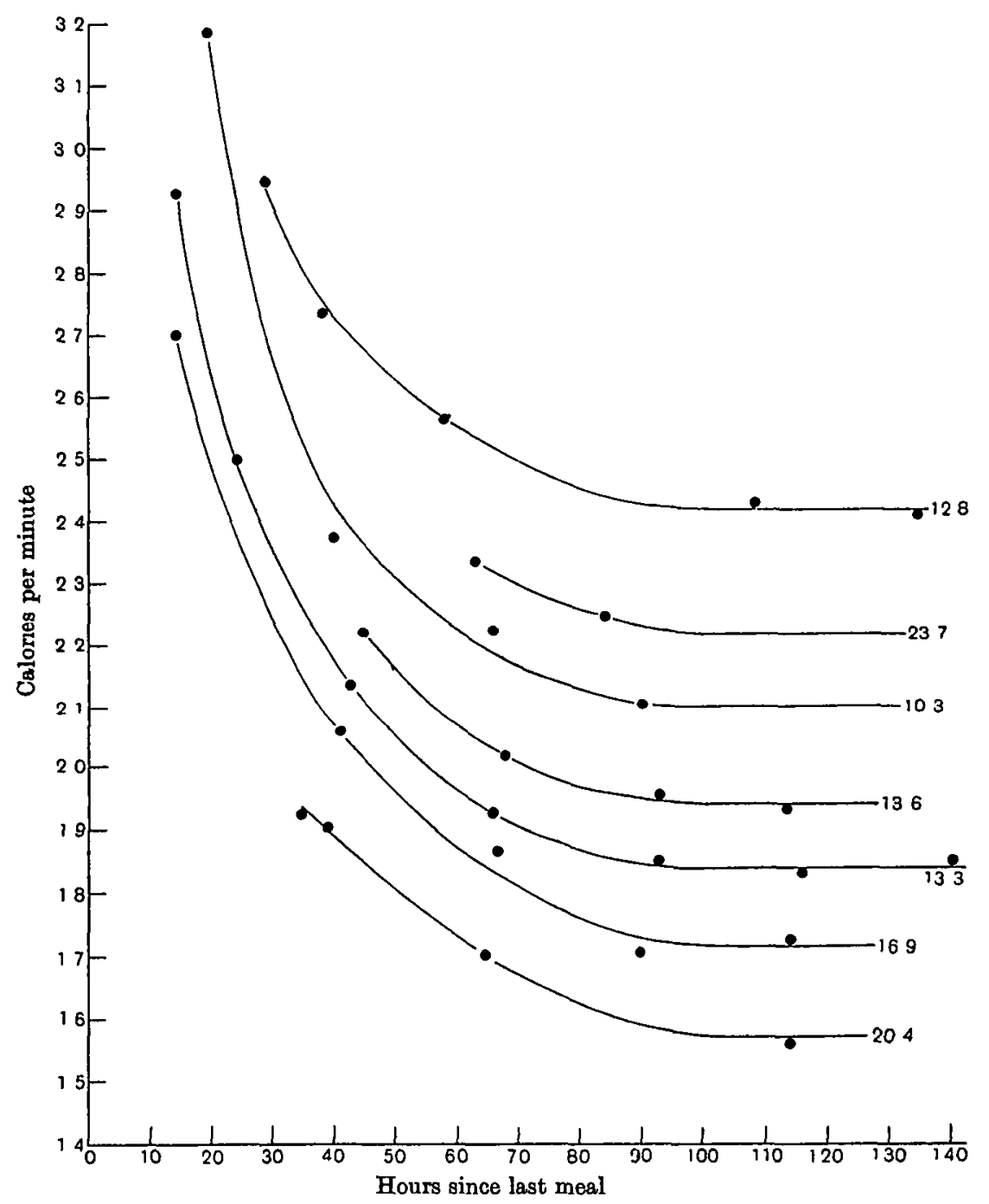

Fig. 2.

Fig. 2 shows the results in Table I plotted on a single diagram. The ordinates are calories per minute and the abscissae are hours since the last meal. The $12.8^{\circ}$ curve is raised 3 cal. and the $23.7^{\circ}$ curve is raised 5 cal. to keep them clear of the other curves. 
It will be seen that the points fall very well on a series of similar curves. The fact that the divergences of the points from the curves are so small affords some evidence of the general accuracy of the measurements and supports the belief of the writers that they have obtained the true resting metabolism.

The curves show a very close similarity to each other as regards their shape. This similarity formed the subject of a paper read by the writers before the Royal Society. The paper has been printed in the Proceedings of the Royal Society ${ }^{1}$ and nothing need be said on the matter here.

The circumstances of the experiment at $23 \cdot 7^{\circ}$ made it impossible to get more than two satisfactory observations and these were both taken before the hog had quite reached his basal metabolism. The basal metabolism was therefore obtained in this case by drawing a curve through the two observed points parallel to the remaining curves. This procedure seems to be justified by the conclusions reached in the paper read before the Royal Society.

Inspection of the curves shows that in every case the terminal horizontal part, which gives the basal metabolism, is reached between 90 and 100 hours after the last meal. Tangl ${ }^{2}$ states that the hogs with which he worked reached their basal metabolism in 72 hours. In the present experiments there was always a perceptible fall after 72 hours. From some experiments which the writers are carrying out at present it would seem that age has an effect on the time at which the basal metabolism is reached, for a young hog weighing about $35 \mathrm{lbs}$. reaches his basal metabolism in about two days.

The basal metabolism is found graphically from the curves in Fig. 2 and is tabulated in the fifth column of Table II below.

Table II.

Summary for Critical Temperature.

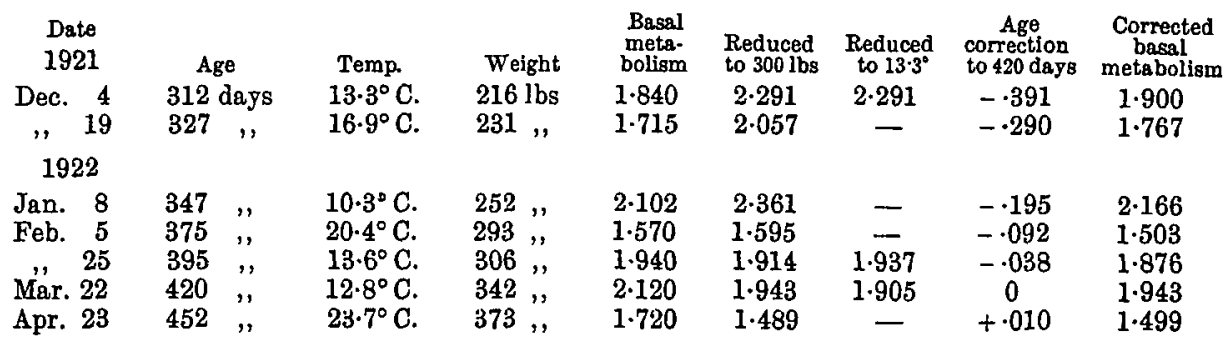


Before the measurements can be used for finding the critical temperature they must be corrected to a standard weight and a standard age.

The standard weight chosen is 300 lbs., as this lies almost half-way between the extremes of weight. In making the correction it is assumed that the metabolism is proportional to the hog's surface area and that the area is proportional to the two-thirds power of the weight.

The basal metabolisms in the sixth column of Table II are calculated from those in the fifth column on these assumptions.

In order to provide data for a possible age correction observations of the basal metabolism were made in the neighbourhood of $13^{\circ} \mathrm{C}$. on December 4, February 25 and March 22. These three were at 13.3', $13.6^{\circ}$ and $12.8^{\circ}$ respectively. The difference is not great, but as they fall at a part of the range where the change of metabolism with temperature is considerable they should be corrected to the same temperature before they are used for finding the age correction.

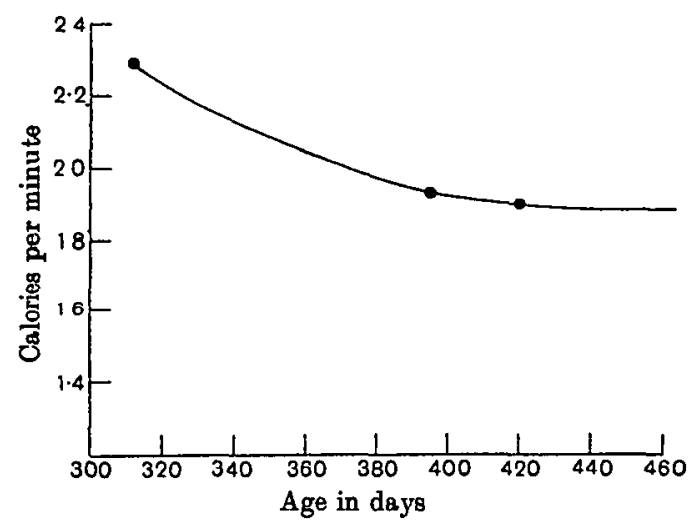

Fig. 3.

This correction requires a knowledge of what it was the object of the experiments to find-namely, the relation between basal metabolism and temperature-and it is somewhat illogical to make such a correction at this stage. As however the correction is quite small it is not likely that any appreciable error will be made by assuming for this purpose that there is a linear relation connecting the metabolism and temperature between $10.3^{\circ}$ and $20.45^{\circ}$. This gives a fall of 077 calories per Centigrade degree, and using this value we have the corrected metabolisms shown in the seventh column of Table II. The final curve of Fig. 4 shows that a linear relation is not far from the truth.

Fig. 3 shows the result of plotting the basal metabolism at $13.3^{\circ}$ 
against the hog's age in days. It appears that at the end of the experiments age had almost ceased to have any effect.

We have next to correct all the metabolisms in the sixth column of Table II to some one date. It is immaterial what date is chosen. The writers have selected March 22 when the hog was 420 days old.

The corrections to be added or subtracted are given in the eighth column of Table II. In making these corrections it has been assumed that the effect of increasing age on the curve connecting metabolism and temperature is to cause it to move bodily downwards always keeping the same shape. It may be that it would be more correct to assume that the various points on the curve move downwards in the same proportion.

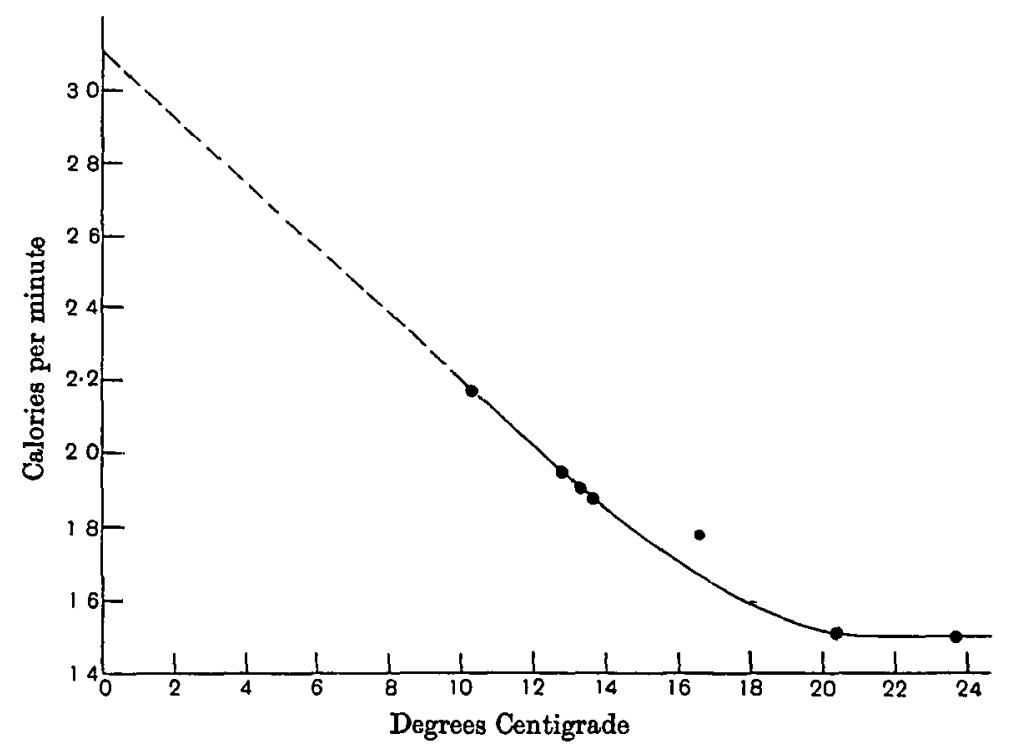

Fig. 4.

The writers see no adequate theoretical reason for preferring either of these methods to the other. For the present purpose it makes very little difference which method is used. The point might be worth investigating experimentally, but it would be difficult to secure the necessary accuracy.

We have finally the corrected values of the basal metabolism shown in the last column of Table II and plotted against temperature in Fig. 4.

The points fall very well on the curve with the exception of that at $16.9^{\circ}$ which is $6 \frac{1}{2}$ per cent. too high. The writers are unable to account for 
this anomaly except on the grounds that the experiment at $16.9^{\circ}$ was unsatisfactory throughout. The hog was scarcely ever really quiet throughout the whole fasting period with the result that the galvanometer curve was less regular than usual. It should be noted that errors due to the hog would almost certainly cause the observed metabolism to be too high, whilst experimental errors would be indifferently high and low. There was also an instrumental failure on the last day of the $16.9^{\circ}$ experiment. One of the electrical heaters in the thermostat burnt out and there was a great disturbance of the curve before the fault could be remedied.

The remaining points however are sufficiently consistent to enable the writers to state that the critical temperature is very near to $21^{\circ} \mathrm{C}$.remembering, however, what has been stated above, that the real average temperature of the hog's surroundings may be somewhat different.

This conclusion agrees very well with that reached by Tangl who states that he found the critical temperature to be between $20^{\circ}$ and $23^{\circ}$.

The actual metabolism at the critical temperature is 1.50 calories per minute for a $300 \mathrm{lb}$. hog or 2,160 calories per day.

The exact relation between a hog's surface area and his weight is not known. Tangl accepts Voit's formula $A=9.02 W^{\frac{2}{3}}$. 'This gives 904 calories per day per square metre, which is near the value generally adopted for human beings.

The values of the basal metabolism at different temperatures have a practical interest for pig breeders as they enable us to calculate the maintenance ration at various temperatures.

Table III.

$\begin{array}{cc}\text { Temp. } & \begin{array}{c}\text { Basal metabolism } \\ \text { of a } 300 \text { lb. hog }\end{array} \\ 0 & 3 \cdot 10 \\ 2 & 2 \cdot 92 \\ 4 & 2 \cdot 74 \\ 6 & 2 \cdot 56 \\ 8 & 2 \cdot 38 \\ 10 & 2 \cdot 19\end{array}$

$\begin{array}{cc} & \begin{array}{c}\text { Basal metabolism } \\ \text { Temp. }\end{array} \\ \text { of a } 300 \mathrm{lb} \text {. hog } \\ 12 & 2.01 \\ 14 & 1.84 \\ 16 & 1.70 \\ 18 & 1.59 \\ 20 & 1.51 \\ 22 & 1.50\end{array}$

Table III gives the metabolism of a $300 \mathrm{lb}$. hog at intervals of $2^{\circ}$ from $0^{\circ} \mathrm{C}$. to $22^{\circ} \mathrm{C}$. The metabolism between $10^{\circ}$ and $20^{\circ}$ is taken from the full curve in Fig. 4. Actual observations of the metabolism could not be made at very low temperatures as the temperature of the town supply water did not permit of the calorimeter being set to anything below $10^{\circ}$. In order to get an estimate of the metabolism below $10^{\circ}$ it is therefore necessary to use the uncertain expedient of extrapolation. 
As the observed curve is nearly a straight line below about $16^{\circ}$ it has been continued backwards in a straight line to $0^{\circ}$, the dotted line being the part of the curve obtained by extrapolation. The values of the metabolism in Table III are taken from this extended curve.

It may be presumed that in so far as the extrapolated values are in error, the error is on the side of their being too low since the observed part of the curve is concave upwards. They will however provide a sufficient approximation for our present purpose.

It will be seen that the maintenance ration at $0^{\circ}$ is more than double that at $22^{\circ}$, and both these temperatures are not unfrequently met with on farms in this country.

\section{CoNCLUSIONS.}

The critical temperature of the hog under experiment was approximately $21^{\circ} \mathrm{C}$.

At this temperature his basal metabolism was a minimum and amounted to 2,160 calories in 24 hours when he was 420 days old and weighed $300 \mathrm{lbs}$. This corresponds to 904 calories per day per square metre of body surface.

As the temperature of his surroundings fell below $21^{\circ} \mathrm{C}$., the basal inetabolism increased at the rate of about 4 per cent. per degree Centigrade, which corresponds to an increase of about 40 per cent. for a temperature difference of $10^{\circ} \mathrm{C}$. which is commonly found between summer and winter conditions.

Thus, if the same law holds in the case of a steer whose basal metabolism at $18^{\circ} \mathrm{C}$. or summer temperature is 6,000 calories, his basal metabolism at $8^{\circ} \mathrm{C}$. in an open yard in winter would be 9,000 calories.

The suggestion is that the increase of 3,000 calories is met by the utilisation of the thermic energy of the coarse fodder included in his ration. 